\title{
Dentinal tubule obliteration using toothpastes containing sodium trimetaphosphate microparticles or nanoparticles
}

\author{
Carla Oliveira Favretto ${ }^{1}$ - Alberto Carlos Botazzo Delbem ${ }^{1} \cdot$ João Carlos Silos Moraes ${ }^{2} \cdot$ Emerson Rodrigues Camargo $^{3}$. \\ Priscila Toninatto Alves de Toledo ${ }^{1} \cdot$ Denise Pedrini ${ }^{4,5}$
}

Received: 16 March 2017 / Accepted: 7 February 2018 / Published online: 20 February 2018

(C) Springer-Verlag GmbH Germany, part of Springer Nature 2018

\begin{abstract}
Objectives This in vitro study evaluated the effect of microparticles (TMPmicro) or nanoparticles (TMPnano) TMP associated with fluoride (F) in toothpaste formulations on the obliteration of dentinal tubules (DT).

Materials and methods The dentinal tubules of bovine dentin blocks were unobstructed by immersion in 37\% phosphoric acid solution. Blocks ( $n=20$ /group) underwent mechanical brushing (2×/day) during 7 days with toothpastes: placebo, $1100 \mathrm{ppm} \mathrm{F}$, and 1100 with 3\% TMPmicro or 3\% TMPnano. After that, ten blocks of each group were immersed in citric acid (pH 3.2) for $1 \mathrm{~min}$. The number, diameter and area of unobstructed DT, atomic $\%$ of chemical elements from precipitates, and the mineral concentration were quantified. Data were submitted to two-way ANOVA, followed by Student-Newman-Keuls test $(P<0.05)$. Results Toothpastes containing TMPmicro and TMPnano promoted greater obliteration of DT and greater mineral concentration compared to other groups $(P<0.05)$. Placebo and $1100 \mathrm{ppm} \mathrm{F}$ group presented similar obliteration but $1100 \mathrm{ppm} \mathrm{F}$ group promoted higher mineral concentration. Higher $\mathrm{Ca} / \mathrm{P}$ ratios were observed in groups treated with $\mathrm{TMP}$; the acid challenge reduced $\mathrm{Ca} / \mathrm{P}$ ratio for all groups. The atomic $\%$ of $\mathrm{C}$ and $\mathrm{N}$ was significantly lower for TMP toothpastes before acid challenge, but increased afterwards.

Conclusions It was concluded that the addition of TMPmicro or TMPnano to F toothpastes produced greater obliteration of dentinal tubules and higher mineral concentration when compared with $1100 \mathrm{ppm}$ F.

Clinical relevance By the addition of TMP, fluoride toothpastes may occlude the dentinal tubules, with potential to reduce dentin hypersensitivity.
\end{abstract}

Keywords Fluorides $\cdot$ Calcium phosphates $\cdot$ Collagen $\cdot$ X-ray microtomography $\cdot$ Nanoparticles $\cdot$ Energy-dispersive X-ray spectroscopy

Denise Pedrini

pedrini@ foa.unesp.br

1 Department of Pediatric Dentistry and Public Health, School of Dentistry, Araçatuba, São Paulo State University (UNESP), Araçatuba, SP, Brazil

2 Department of Physics and Chemistry, São Paulo State University (UNESP), Ilha Solteira, SP, Brazil

3 Department of Chemistry, Federal University of São Carlos UFSCAR, São Carlos, SP, Brazil

4 Department of Surgery and Integrated Clinic, School of Dentistry, Araçatuba, São Paulo State University (UNESP), Araçatuba, SP, Brazil

5 Disciplina de Clínica Integrada, Faculdade de Odontologia do Campus de Araçatuba, UNESP, Rua José Bonifácio 1193, CEP, Araçatuba, SP 16015-050, Brazil

\section{Introduction}

Dentin exposure at the cervical tooth region is associated with dentin hypersensitivity. According to the hydrodynamics theory [1], the occlusion of dentinal tubules is the main method to treat hypersensitive teeth because it reduces the fluid flow inside the tubules, thus relieving the sensitivity symptoms [2-7]. Considering that acidic substances open the dentinal tubules $[8,9]$, an ideal agent for promoting dentinal tubule obliteration should, therefore, be acid resistant.

The most common agents that promote plugging of dentinal tubules are sodium fluoride, stannous fluoride, strontium salts, calcium phosphate, calcium carbonate, arginine, and bioactive glasses $[10,11]$. Also, toothpastes are the most common vehicles for incorporation of desensitizing agents, especially due to their relative low 
cost, ease of use, and possibility of home application [12, 13]. Besides producing occlusion of dentinal tubules, they must maintain their effects in the presence of acid challenge, mechanical removal, and salivary clearance [10]. Also, saliva contains proteins and ions that can interfere with the adsorption of desensitizing agents on the surface or solubilize them [13].

Agents intended to produce the occlusion of dentinal tubules must have affinity to collagen or hydroxyapatite. Phosphates, such as sodium trimetaphosphate (TMP), have a strong affinity to $\mathrm{OH}^{-}$sites of hydroxyapatite $[14,15]$. The addition of $3 \%$ TMP to fluoride toothpastes $(1100 \mathrm{ppm})$ has been shown to reduce enamel demineralization when compared to conventional toothpastes [16]. This effect was greater adding TMP nanoparticles to conventional $\mathrm{F}$ toothpastes [17]. Based on the above, it would be interesting to verify whether a TMP-containing toothpaste also presents capacity to promote the obliteration of dentinal tubules.

Therefore, the aim of this study was to evaluate the ability of fluoride toothpastes (1100 ppm F) containing TMP in promoting the obliteration of dentinal tubules with or without acid challenge. The study also aimed to verify whether reducing TMP particle size would further enhance such effects. The null hypotheses were that TMP-containing fluoride toothpastes have a similar ability to occlude dentinal tubules as a toothpaste with $1100 \mathrm{ppm} \mathrm{F}$, that acid challenge does not alter the obliteration of dentinal tubules, and that particle size does not influence the results.

\section{Materials and methods}

\section{Specimen preparation}

Dentin blocks $(4 \times 4 \times 2 \mathrm{~mm})$ were obtained from the region below the dentinoenamel junction of bovine incisor roots $(n=90)$, previously sterilized in a microwave at $650 \mathrm{~W}$, for $3 \mathrm{~min}$ [18]. The outer root surface was ground flat with water-cooled silicon carbide paper disks (600 and 1200 grades; Extec, Enfield, CT, USA), $20 \mathrm{~s}$ each, and cleaned in ultrasound (Unique USC 1400, Indaiatuba, SP, Brazil) at $40 \mathrm{~Hz}$ and $135 \mathrm{~W}$ during $20 \mathrm{~min}$ at room temperature. Thereafter, the blocks were immersed during $30 \mathrm{~s}$ in a solution $(1 \mathrm{~mL} / \mathrm{block})$ of $37 \%$ phosphoric acid [19], washed with deionized water for $30 \mathrm{~s}$, and dried with paper towel, for removal of the smear layer on both sides of the blocks. The remaining cellular or extracellular elements in the interior of dentinal tubules were removed by immersion during $12 \mathrm{~h}$ in a solution $(1 \mathrm{~mL} / \mathrm{block})$ of $10 \%$ $\mathrm{NaOH}[20,21]$, followed by further $12 \mathrm{~h}$ of immersion in distilled water $(3 \mathrm{~mL} / \mathrm{block})$.

\section{Toothpaste formulation and fluoride assessment}

The toothpastes were produced with the following components: titanium dioxide, carboxymethyl cellulose, methyl-phydroxybenzoate sodium, saccharin, mint oil, glycerin, abrasive silica, sodium lauryl sulfate, and deionized water. Toothpastes containing 3\% of microparticles TMP (Aldrich Chemistry, CAS 7785-84-4, China) with average particle size of approximately $400 \mathrm{~nm}$ (TMPmicro) or $3 \%$ of nanoparticles TMP with average size of $25 \mathrm{~nm}$ (TMPnano) were prepared [22]. NaF (Merck, CAS 7681-49-4, Germany) was added to these toothpastes to reach a concentration of $1100 \mathrm{ppm} \mathrm{F}$. In addition, toothpastes without TMP and F (placebo) as well as with 1100 ppm F (without TMP) were prepared. The toothpastes used in this study were stored at room temperature and kept closed to prevent any change. The total (TF) and ionic (IF) fluoride concentrations were determined [23] prior to their use. The mean (SD) concentration of TF and IF $(n=3)$ for the placebo toothpaste were $12.0 \mathrm{ppm}(0.9)$ and $11.0 \mathrm{ppm}$ (0.7), respectively. For toothpastes with $1100 \mathrm{ppm}$ F, the corresponding mean values (SD) among groups were 1135.4 ppm (52.4) and $1019.1 \mathrm{ppm}$ (85.9).

\section{Saliva collection}

Saliva collections were performed in accordance with the protocol approved by the Institutional Review Board (CAAE: 20419113.0.0000.5420), after the individuals provided signed informed consent. Paraffin-stimulated saliva samples from healthy donors of both genders (aged 22-35 years, $n=6$ ) were collected into ice-chilled vials and subsequently pooled. Saliva collection was performed at morning $1 \mathrm{~h}$ after breakfast. Immediately after collection, whole saliva samples were centrifuged for $20 \mathrm{~min}$ at $4{ }^{\circ} \mathrm{C}$ and $2000 \times g$. The supernatants were divided into $50-\mathrm{mL}$ aliquots and stored at $-80^{\circ} \mathrm{C}$ [24].

\section{Experimental groups}

Dentin blocks were randomly allocated into four groups $(n=$ 20/group) according to the experimental toothpastes: placebo (no F and TMP), 1100 ppm F, 1100 ppm F + 3\% microparticles TMP (1100 TMPmicro), and $1100 \mathrm{ppm} \mathrm{F}+3 \%$ nanoparticles TMP (1100 TMPnano). Ten dentin blocks were not subjected to any treatment and served as control. There are no data for this bovine dentin region concerning the number, area, and diameter of dentinal tubules as well as atomic $\%$ of hydroxyapatite and collagen components.

\section{Experimental phase}

Before each treatment, the blocks were immersed in human saliva ( $3 \mathrm{~mL} / \mathrm{block})$ at room temperature during $1 \mathrm{~h}$. Following, the blocks were subjected to mechanical 
brushing using an automated machine (MSET, Elquip, São Carlos, SP, Brazil), at 150 strokes per minute during 2 min [7] and axial load of $150 \mathrm{~g}$. During brushing, the blocks were immersed in $2 \mathrm{~mL}$ of toothpaste slurry $(3 \mathrm{~mL}$ of deionized water: $1 \mathrm{~g}$ of toothpaste) at $37{ }^{\circ} \mathrm{C}$. Blocks were then gently washed with deionized water for $30 \mathrm{~s}$. This treatment was carried out two times a day, at 8 am and $5 \mathrm{pm}$ [7], and the blocks were kept immersed in human saliva between these periods. After the second treatment, the blocks remained immersed during $1 \mathrm{~h}$ in human saliva. Subsequently, they were stored in artificial saliva $\left(1.5 \mathrm{~mol} / \mathrm{L} \mathrm{Ca}\left(\mathrm{NO}_{3}\right)_{2} .4 \mathrm{H}_{2} \mathrm{O}, 150 \mathrm{~mol} / \mathrm{L} \mathrm{KCl}\right.$, $0.9 \mathrm{~mol} / \mathrm{L} \mathrm{NaH} \mathrm{PO}_{4} \cdot \mathrm{H}_{2} \mathrm{O}, 0.1 \mathrm{~mol} / \mathrm{L}$ Tris; $37{ }^{\circ} \mathrm{C} ; 3 \mathrm{~mL} /$ block) [16] until the next day at $37{ }^{\circ} \mathrm{C}$ to minimize bacterial and fungal proliferation and to reduce the need of great volume of human saliva. Human and artificial saliva were renewed daily. At the end of 7 days, ten blocks of each group were immersed in citric acid $(3 \mathrm{~mL} /$ block, $\mathrm{pH}$ 3.2) $[25,26]$ during $1 \mathrm{~min}$, under constant stirring $\left(37^{\circ} \mathrm{C}\right)$, and washed with deionized water for $1 \mathrm{~min}$. All blocks were analyzed regarding the obliteration of dentinal tubules, atomic quantification of elements in the precipitates on the dentinal surface, and mineral concentration.

\section{Scanning electron microscopy}

Dentin blocks were fitted in stubs using double-sided carbon tape and taken to a sputter coating machine (QuorumQ150T E), being covered by a thin layer of gold. The images from each specimen were obtained by scanning electron microscopy (SEM) (Carl Zeiss, EVO ILS15, Carl Zeiss NTS LTD, Germany) at $20 \mathrm{kV}$ and $\times 3000$ magnification. The images were evaluated as to the number of dentinal tubules $\left(\mathrm{mm}^{2}\right)$, considering a total area of

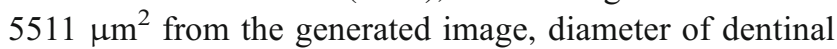
tubules, and area of open tubules. For analysis, ImageJ software version 1.47s (NIH, Bethesda, MD, USA) was used to delimit the open tubules with the "Paintbrush" tool, followed by adjusting the image for brightness and contrast at maximum and threshold with "Image" tool. The area and Feret's diameter were selected using the "Set Measurements" tool into "Analyze" tool in the ImageJ software. Afterwards, the "Analyze Particles" tool into "Analyze" tool was utilized for quantification. All analyses were performed by a previously trained and calibrated examiner. The intra-examiner reliability was evaluated using 15 randomized specimens after 30 days, and the kappa coefficient of reproducibility was 0.944 for area, 0.841 for diameter, and 0.956 for number analysis. Another examiner evaluated the same 15 specimens, and the inter-examiner agreement was 0.941, 0.976, and 0.963 , respectively.

\section{Energy-dispersive X-ray}

The specimens were examined by energy-dispersive X-ray (Oxford Instruments, INCAx - act, $133 \mathrm{eV}$, England) to determine the presence of chemical elements deposited on the dentin surface of each block. The dentin surface was slight sputter coated with a gold layer of $\sim 5 \mathrm{~nm}$ during $90 \mathrm{~s}$. The spectral analysis was obtained from $20 \mathrm{kV}$, an area of $5511 \mu \mathrm{m}^{2}$, spatial resolution at $\sim 2 \mu \mathrm{m}$, and the count time was $150 \mathrm{~s}$. Quantitative analysis reported the presence of carbon (C), nitrogen $(\mathrm{N})$, oxygen $(\mathrm{O})$, sodium $(\mathrm{Na})$, magnesium $(\mathrm{Mg})$, phosphorus $(\mathrm{P})$, calcium $(\mathrm{Ca})$, titanium $(\mathrm{Ti})$, potassium $(\mathrm{K})$, silica $(\mathrm{Si})$, and fluorine $(\mathrm{F})$. Atomic \% values were considered above $1 \%$ to allow comparison between groups.

\section{Computed X-ray microtomography}

The dentin blocks were sectioned through the center longitudinally and transversally along the flat portion using a precision saw (IsoMet 1000, Buehler, Lake Bluff, IL, USA) with two diamond disks (series 15HC 11-4243, Diamond, Buehler) and a spacer disk (1-mm thickness) refrigerated with deionized water, providing specimens of $1 \times 1 \mathrm{~mm}$ for analysis of computed X-ray microtomography (SkyScan1272 highresolution Micro-CT, Bruker-Micro-CT, Kontich, Belgium). The micro-CT was operated at $60 \mathrm{kV}$ and $166 \mu \mathrm{A}$, aluminum filter at $0.25 \mathrm{~mm}$, spatial resolution at $1.5 \mu \mathrm{m}$, rotation step at $0.600^{\circ}$, and random movement at 13 . The projections of images were reconstructed utilizing the NRecon software (version 1.6.10.2, Skyscan1272, Bruker Micro-CT) and smoothing at 4 , ring artifact correction at 7 , and beam hardening correction at $60 \%$. Following image reconstruction, twodimensional virtual slices in sagittal and coronal planes were obtained using the Data Viewer software (Skyscan1272). The stacked 2D was imported into ImageJ software to produce an overall mineral concentration $\left(\mathrm{g}_{\mathrm{HAp}} \mathrm{cm}^{-3}\right)$ profile as a function of depth $(\mu \mathrm{m})$ based on the mass attenuation coefficients of inorganic (hydroxyapatite) and organic components (water and protein) $[27,28]$.

In subsequent analyses, the mineral patterns in dentin were evaluated by the differential mineral concentration profiles, by subtracting the mineral concentration of the control group from those of the toothpastes groups (i.e., placebo, 1100 ppm F, 1100 TMPmicro, and 1100 TMPnano group values minus the control group values) at each depth. These differential profiles were then integrated up to $250 \mu \mathrm{m}$ to yield the values of integrated mineral area (IM).

\section{Statistical analysis}

The number, diameter and area of dentinal tubules, atomic $\%$ of the elements, and IM $\left(\mathrm{g}_{\mathrm{HAp}} \mathrm{cm}^{-3} \times \mu \mathrm{m}\right)$ were considered as variables, and toothpastes and acid challenge as variation 

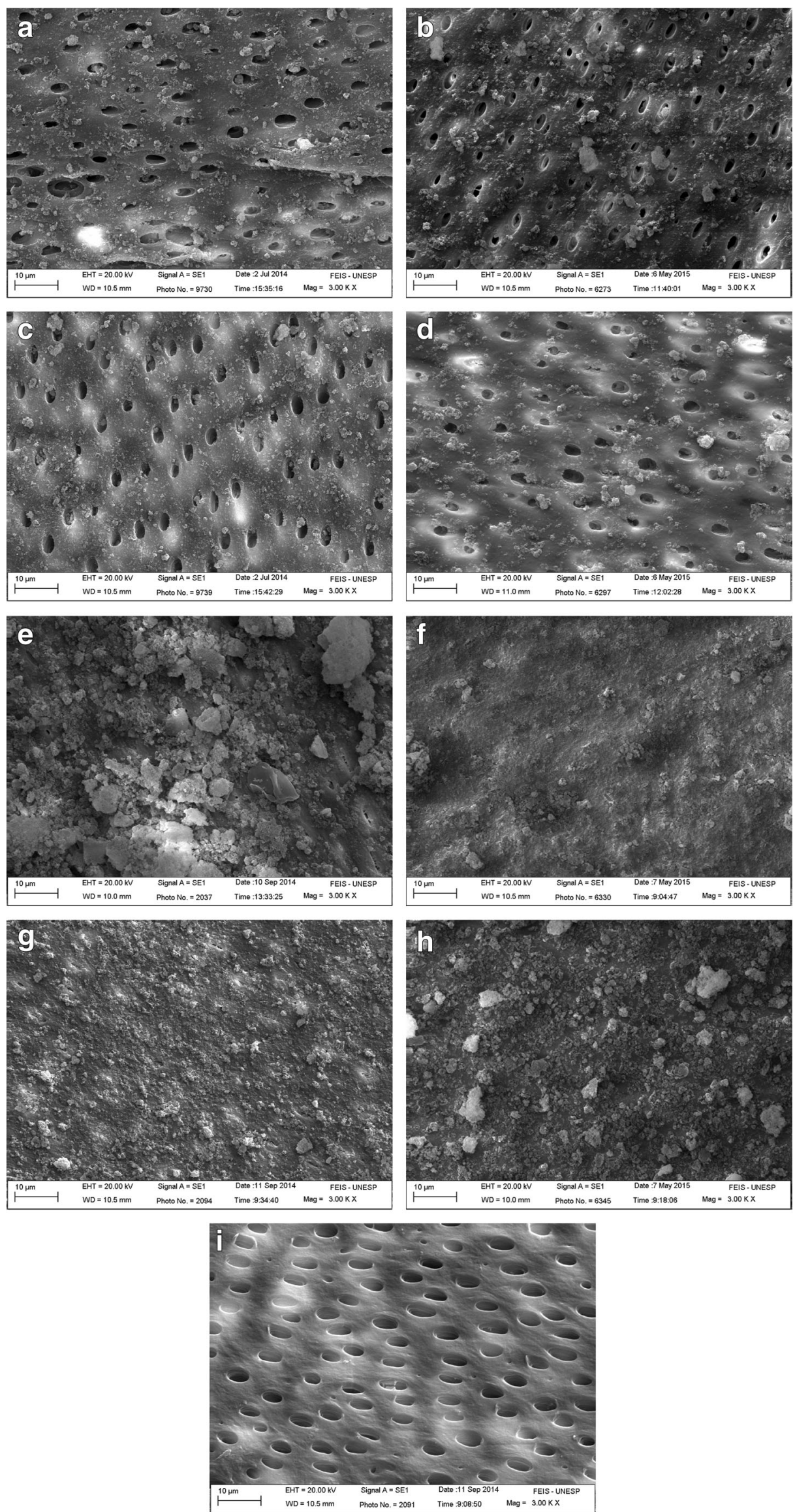
Fig. 1 Photomicrographs of dentin surface according to the treatments obtained by SEM ( $\times 3000$ magnification). Placebo $(\mathbf{a}, \mathbf{b}), 1100 \mathrm{ppm} \mathrm{F}(\mathbf{c}$, d), 1100 TMPmicro $(\mathbf{e}, \mathbf{f})$, and 1100 TMPnano $(\mathbf{g}, \mathbf{h})$ after treatment and after treatment followed by acid challenge, respectively. Control (i)

factors. The variables presented normal and homogeneous distribution and were analyzed by two-way ANOVA, followed by the Student-Newman-Keuls test. Pearson's correlation was calculated for number, area, and diameter of dentinal tubules. Analyses were performed using the SigmaPlot software (version 12.0) at a significance level of 5\%.

\section{Results}

\section{SEM}

SEM images showed open dentinal tubules in the control group (Fig. 1i), while the presence of precipitate was observed for treated groups (Fig. 1a-h). Treatment with placebo and $1100 \mathrm{ppm} F$ toothpastes produced minor amount of precipitate both on surface and into the dentinal tubules (Fig. 1a, c). These groups presented similar number, diameter, and area of open dentinal tubules $(P>0.142)$. Conversely, the precipitates were shown to fully cover the dentinal surface after fluoride toothpastes with TMPmicro and TMPnano treatment (Fig. 1e, g), obliterating all dentinal tubules. The number, diameter, and area of dentinal tubules were smaller for blocks treated with TMP-containing toothpastes $(P<0.001)$ compared with placebo and $1100 \mathrm{ppm} F$ groups (Table 1). Nevertheless, the quantitative results were similar $(P>0.745)$ between 1100 TMPmicro and 1100 TMPnano (Table 1). The pattern of the precipitate was similar between groups submitted or not to acid challenge. Notwithstanding, only the TMPmicro group presented smaller number and diameter of dentinal tubules after acid challenge $(P=0.016)$. A precipitate layer covering the dentinal tubules was visible in TMPmicro and TMPnano groups (Fig. 1f, h), with smaller particles mainly in the toothpaste with TMPnano. Significant correlations were observed between number and area (Pearson's $r=0.719$ ), number and diameter (Pearson's $r=0.778$ ), and diameter and area (Pearson's $r=0.923$ ) of dentinal tubules.

\section{Energy-dispersive X-ray}

Energy-dispersive $\mathrm{X}$-ray (EDX) analysis revealed significant quantities of the chemical elements $\mathrm{Ca}, \mathrm{P}, \mathrm{C}, \mathrm{N}$, and $\mathrm{O}$ on surface dentin (Table 2). Others, such as F, Si, K, Na, Ti, and $\mathrm{Mg}$, appeared as trace elements $(<1 \%)$ and not in all specimens. After treatment, the amounts of $\mathrm{Ca}, \mathrm{P}$, and $\mathrm{C}$ were similar between groups $(P=0.157)$. The groups treated with TMP showed lower amounts of $\mathrm{N}(P<0.005)$ and higher of $\mathrm{O}$ $(P<0.004)$ compared to placebo and $1100 \mathrm{ppm} \mathrm{F}$ (Table 2). After treatment followed by acid challenge, the quantities of $\mathrm{Ca}$ and $\mathrm{P}$ were lower for all groups compared to those not subjected to acid challenge $(P<0.034)$. The atomic \% values of $\mathrm{Ca}$ and $\mathrm{N}$ were similar between groups $(P>0.078)$. In addition, similar values of $\mathrm{N}$ were observed for the placebo and $1100 \mathrm{ppm} \mathrm{F}$ groups, regardless of the acid challenge $(P<0.293)$. Groups treated with TMP-containing toothpastes showed higher values of $\mathrm{N}$ after acid challenge $(P<0.001)$, while larger amount of $\mathrm{C}$ was attained in blocks treated with TMP-containing toothpastes $(P<0.009)$ compared to placebo and $1100 \mathrm{ppm} F$ groups (Table 2). All fluoride toothpastes promoted significantly higher values of $\mathrm{C}(P<0.011)$ and lower values of $\mathrm{O}(P<0.042)$ after acid challenge.

Table 1 Mean values (SD) of area, diameter, and number of dentinal tubules calculated from SEM images and integrated mineral area (IM) from micro-CT, after treatment (no acid) and after treatment followed by acid challenge (acid)

\begin{tabular}{|c|c|c|c|c|c|c|}
\hline \multirow[t]{2}{*}{ Variables } & \multirow{2}{*}{ Challenge } & \multicolumn{5}{|l|}{ Treatment } \\
\hline & & Placebo & 1100 ppm F & 1100 TMPmicro & 1100 TMPnano & Control \\
\hline Area $\left(\mu \mathrm{m}^{2}\right)$ & $\begin{array}{l}\text { No acid } \\
\text { Acid }\end{array}$ & $\begin{array}{l}3,221.3 \text { a, A (897.5) } \\
3,000.0 \text { a, A (857.8) }\end{array}$ & $\begin{array}{l}3,530.3 \text { a, A }(1,430.2) \\
3,645.4 \text { a, A }(1,631.5)\end{array}$ & $\begin{array}{l}1,547.7 \text { b, A (285.4) } \\
916.0 \text { b, A }(790.1)\end{array}$ & $\begin{array}{l}1,470.8 \mathrm{~b}, \mathrm{~A}(457.9) \\
1,202.6 \mathrm{~b}, \mathrm{~A} \\
\quad(1,066.2)\end{array}$ & $6,083.6(2,239.0)$ \\
\hline Diameter $(\mu \mathrm{m})$ & $\begin{array}{l}\text { No acid } \\
\text { Acid }\end{array}$ & $\begin{array}{l}2,665.0 \mathrm{a}, \mathrm{A}(374.9) \\
2,520.2 \mathrm{a}, \mathrm{A}(515.0)\end{array}$ & $\begin{array}{l}2,883.2 \text { a, A (546.1) } \\
2,803.1 \text { a, A (738.4) }\end{array}$ & $\begin{array}{l}1,672.1 \text { b, A (178.3) } \\
987.9 \text { b, B (859.1) }\end{array}$ & $\begin{array}{l}1,603.3 \mathrm{~b}, \mathrm{~A}(209.9) \\
1,164.9 \mathrm{~b}, \mathrm{~A} \\
\quad(1,020.9)\end{array}$ & $3,440.5(872.5)$ \\
\hline $\begin{array}{l}\text { Number of tubules } \\
\quad\left(\mathrm{mm}^{2}\right)\end{array}$ & $\begin{array}{l}\text { No acid } \\
\text { Acid }\end{array}$ & $\begin{array}{c}15,004.2 \mathrm{a}, \mathrm{A} \\
(2,336.1) \\
11,829.2 \mathrm{a}, \mathrm{B} \\
(5,299.8)\end{array}$ & $\begin{array}{c}14,732.1 \mathrm{a}, \mathrm{A} \\
(2,732.6) \\
14,097.1 \mathrm{a}, \mathrm{A} \\
(3,680.7)\end{array}$ & $\begin{array}{c}4,717.2 \mathrm{~b}, \mathrm{~A} \\
(1,294.3) \\
1,796.2 \mathrm{~b}, \mathrm{~B} \\
(2,536.3)\end{array}$ & $\begin{array}{c}4,717.2 \mathrm{~b}, \mathrm{~A} \\
(1,640.7) \\
2,159.0 \mathrm{~b}, \mathrm{~B} \\
(2,722.7)\end{array}$ & $\begin{array}{l}21,318.0 \\
\quad(3,760.5)\end{array}$ \\
\hline $\mathrm{IM}\left(\mathrm{g}_{\mathrm{HAp}} \mathrm{cm}^{-3} \times \mu \mathrm{m}\right)$ & $\begin{array}{l}\text { No acid } \\
\text { Acid }\end{array}$ & $\begin{array}{l}4.04 \mathrm{a}, \mathrm{A}(1.06) \\
2.53 \mathrm{a}, \mathrm{B}(0.67)\end{array}$ & $\begin{array}{l}6.31 \mathrm{~b}, \mathrm{~A}(1.65) \\
8.12 \mathrm{~b}, \mathrm{~A}(3.12)\end{array}$ & $\begin{array}{l}15.04 \mathrm{c}, \mathrm{A}(3.48) \\
16.11 \mathrm{c}, \mathrm{A}(2.50)\end{array}$ & $\begin{array}{l}11.85 \text { c, A (2.18) } \\
14.61 \text { c, A }(3.66)\end{array}$ & - \\
\hline
\end{tabular}

Distinct lowercase letters indicate statistical difference between treatments for each variable and challenge. Different uppercase letters indicate differences between challenge for each treatment and variable (Student-Newman-Keuls' method, $n=10, P<0.05$ ) 


\section{Computed X-ray microtomography}

Cross-sectional and differential profiles showed higher mineral concentration at the $\sim 50-\mu \mathrm{m}$ outer regions of dentin, mainly for TMP-containing toothpastes (Fig. 2). Data from Fig. 2c, d were used to calculate the IM described in Table 1. Treatment with TMP showed higher mineral concentration (IM) in comparison with other treatments $(P<0.001)$ (Table 1$) ; 1100 \mathrm{ppm}$ F group presented higher values than the placebo group $(P=$ $0.002)$. After treatment followed by acid challenge, a lower value of IM was observed for the placebo group $(P=0.001)$, while no significant differences were observed for the other groups $(P>0.157)$. The particle size (microparticle and nanoparticle) did not affect the results $(P>0.099)$.

\section{Discussion}

This study evaluated the capacity of fluoride toothpastes containing TMP in the obliteration of dentinal tubules. The results showed that addition of TMP leads to greater obliteration of dentinal tubules and increases dentin mineral concentration compared to $1100 \mathrm{ppm} F$ toothpaste. However, the particle size did not influence the effect of TMP. Thus, the null hypothesis was partially rejected. Although precipitates were observed in dentin for all treatments, the deposits promoted by TMP led to $56 \%$ greater dentinal obliteration than observed for the $1100 \mathrm{ppm} F$ toothpaste.

The precipitates were formed essentially by calcium phosphate, since higher atomic $\%$ of $\mathrm{Ca}, \mathrm{P}$, and $\mathrm{O}$ was observed for blocks treated with toothpastes compared to the control group (Table 2) [29]. As anionic groups from TMP $\left(\mathrm{P}^{-} \mathrm{O}^{-}\right)$can bind to the amino $\left(\mathrm{NH}_{2}\right)[29,30]$ or hydroxyl $(\mathrm{OH})[14,15]$ groups of collagen protein, the dentin surface becomes more anionic and therefore more prone to the binding of cations. Once adsorbed to dentin, TMP works as a nucleating agent for precipitation of calcium phosphates [29, 30]. This adsorption may occur even when the tooth surface was previously treated with human saliva (as in the present study), or in the presence of acquired pellicle [17, 31,32] or dental biofilm [33]. When the dentin treated with fluoride and TMP is exposed to a medium rich in calcium and phosphate (such as human or artificial saliva), there is higher calcium phosphate deposition (Table 1 and Fig. 2), raising its mineral concentration in 3- to 4-fold (Table 1) in comparison with placebo toothpaste. Interestingly, similar obliteration capacity was observed for the placebo and $1100 \mathrm{ppm} F$ toothpaste, even though different mineral contents were observed between these groups (Table 1 and Fig. 2).

Regardless of the treatment, the mineral concentration is increased into the dentinal tubules (Fig. 2), probably where the treatments penetrated more easily. As TMP promotes a more anionic dentin, there is greater calcium and phosphate flow into the dentinal tubules, which explains the higher mineral concentration in depth (Fig. 2). The deposition of calcium phosphate on collagen fibers can be related to lower amount of $\mathrm{C}$ and $\mathrm{N}$ detected for all groups. The great atomic $\%$ of $\mathrm{C}$ and $\mathrm{N}$ observed in the control group is due to the process of smear and cellular debris removal in the dentinal tubules, exhibiting large amount of collagen. This precipitate (on the surface and on the tubules walls), despite not obliterating the tubules in the placebo and $1100 \mathrm{ppm} F$ toothpastes, was able to increase the concentration of mineral dentin and limit the detection of the major constituent of collagen $(\mathrm{C}$ and $\mathrm{N})$. The lowest atomic percentage of $\mathrm{C}$ and $\mathrm{N}$ with TMP-containing toothpastes (Table 2) was a consequence of greater precipitation of calcium phosphate (no acid), mainly at $20-\mu \mathrm{m}$ outer dentin (Fig. 2). The $\mathrm{Ca} / \mathrm{P}$ ratio was 1.67 for TMPmicro and 1.68 for TMPnano (Table 2), which may be assumed to be alike hydroxyapatite [34]. The control group presented a $\mathrm{Ca} / \mathrm{P}$ ratio of 1.57 , which would indicate the presence of carbonated apatite [35] that composes the mineral part of dentin [36]. The immersion of dentin in saliva (human and artificial) led to precipitation of calcium phosphate no-apatite (placebo group), which resembles tricalcium phosphate considering the $\mathrm{Ca} / \mathrm{P}$ ratio of 1.47 [34]. It is important to point out that the $\mathrm{Ca} / \mathrm{P}$ ratio obtained from EDX cannot indicate the phase of calcium phosphate and whether it is crystalline (apatite) or amorphous $[34,35]$. Thus, the relationship between $\mathrm{Ca} / \mathrm{P}$ ratio and type of calcium phosphate formed must be considered with caution, since the precipitates on dentin surface must contain different phases and quantities of calcium phosphates.

It is known that, when dentin is treated with fluoride, there is deposition of $\mathrm{CaF}_{2}$ that further leads to reduction of dentinal permeability [10]. Nevertheless, it appears that dentin coverage with $\mathrm{CaF}_{2}$ using a concentration of $1100 \mathrm{ppm} \mathrm{F}$ or less is not able to stimulate the precipitation of apatite [2], since the $\mathrm{Ca} / \mathrm{P}$ ratio was 1.48 . This can explain why placebo and $1100 \mathrm{ppm} F$ groups showed the same rate of dentinal obliteration. Nevertheless, the deposits produced by 1100 toothpaste on dentin were more resistant to acid challenge than placebo toothpaste, since the mineral concentration did not decrease (Table 1 and Fig. 2) with 1100 ppm F toothpaste, probably due to the presence of calcium fluoride. This can have an impact on dentin hypersensitivity, which yet needs to be proven. The fact is that apatite deposition on collagen is difficult due to the lack of nucleation sites for apatite formation [29]. However, the addition of TMP provides nucleation sites for apatite precipitation. Unlike most in vitro studies, the present research employed human saliva during the treatment cycles to provide, in addition to calcium and phosphate ions, the formation of acquired pellicle on dentin surface, as observed in vivo. Even though the acquired pellicle produces biomineralization and protection against acid attack, since the proteins contained in the pellicle (i.e., statherins and histatin) have high affinity for calcium and phosphate ions [37]; it is not possible to 
Table 2 Mean values (SD) of atomic \% from chemical element after treatment (no acid) and after treatment followed by acid challenge (acid)

\begin{tabular}{|c|c|c|c|c|c|c|}
\hline \multirow[t]{2}{*}{ Chemical element } & \multirow[t]{2}{*}{ Challenge } & \multicolumn{5}{|l|}{ Treatment } \\
\hline & & Placebo & 1100 ppm F & 1100 TMPmicro & 1100 TMPnano & Control \\
\hline $\mathrm{Ca}$ & $\begin{array}{l}\text { No acid } \\
\text { Acid }\end{array}$ & $\begin{array}{l}15.17 \text { a, A (2.92) } \\
10.55 \text { a, B (2.94) }\end{array}$ & $\begin{array}{l}15.59 \text { a, A (2.21) } \\
11.57 \mathrm{a}, \mathrm{B}(1.71)\end{array}$ & $\begin{array}{l}\text { 17.47a, A (4.76) } \\
13.13 \text { a, B (3.42) }\end{array}$ & $\begin{array}{l}18.47 \text { a, A (5.35) } \\
11.49 \text { a, B (3.67) }\end{array}$ & $11.84(4.13)$ \\
\hline $\mathrm{P}$ & $\begin{array}{l}\text { No acid } \\
\text { Acid }\end{array}$ & $\begin{array}{l}10.50 \mathrm{a}, \mathrm{A}(2.36) \\
8.37 \mathrm{a}, \mathrm{B}(2.13)\end{array}$ & $\begin{array}{l}10.62 \mathrm{a}, \mathrm{A}(1.26) \\
8.24 \mathrm{a}, \mathrm{B}(1.40)\end{array}$ & $\begin{array}{l}10.48 \text { a, A (1.31) } \\
8.94 \text { a, A (2.89) }\end{array}$ & $\begin{array}{l}10.95 \mathrm{a}, \mathrm{A}(0.78) \\
7.33 \mathrm{~b}, \mathrm{~B}(2.03)\end{array}$ & $7.65(2.59)$ \\
\hline $\mathrm{C}$ & $\begin{array}{l}\text { No acid } \\
\text { Acid }\end{array}$ & $\begin{array}{l}31.29 \text { a, A (6.53) } \\
36.10 \mathrm{a}, \mathrm{A}(4.75)\end{array}$ & $\begin{array}{l}27.23 \mathrm{a}, \mathrm{b}, \mathrm{A}(3.77) \\
35.45 \mathrm{a}, \mathrm{B}(5.17)\end{array}$ & $\begin{array}{l}23.96 \mathrm{~b}, \mathrm{~A}(1.47) \\
42.16 \mathrm{~b}, \mathrm{~B}(6.23)\end{array}$ & $\begin{array}{l}24.93 \text { b, A (1.54) } \\
43.39 \text { b, B (9.38) }\end{array}$ & $60.09(4.02)$ \\
\hline $\mathrm{N}$ & $\begin{array}{l}\text { No acid } \\
\text { Acid }\end{array}$ & $\begin{array}{l}8.46 \mathrm{a}, \mathrm{A}(5.25) \\
12.75 \mathrm{a}, \mathrm{B}(2.83)\end{array}$ & $\begin{array}{l}10.87 \mathrm{a}, \mathrm{A}(5.70) \\
11.57 \mathrm{a}, \mathrm{A}(2.22)\end{array}$ & $\begin{array}{l}4.16 \text { b, A (2.68) } \\
10.84 \text { a, B (1.60) }\end{array}$ & $\begin{array}{l}2.91 \mathrm{~b}, \mathrm{~A}(1.76) \\
11.81 \mathrm{a}, \mathrm{B}(1.29)\end{array}$ & $12.13(1.59)$ \\
\hline $\mathrm{O}$ & $\begin{array}{l}\text { No acid } \\
\text { Acid }\end{array}$ & $\begin{array}{l}28.11 \text { a, A (12.46) } \\
26.39 \text { a, A (3.36) }\end{array}$ & $\begin{array}{l}33.70 \text { a, A (12.37) } \\
26.18 \text { a, B (4.37) }\end{array}$ & $\begin{array}{l}43.40 \mathrm{~b}, \mathrm{~A}(8.13) \\
22.32 \mathrm{a}, \mathrm{B}(3.52)\end{array}$ & $\begin{array}{l}42.32 \mathrm{~b}, \mathrm{~A}(2.93) \\
23.95 \mathrm{a}, \mathrm{B}(4.46)\end{array}$ & $8.08(1.84)$ \\
\hline
\end{tabular}

Distinct lowercase letters indicate statistical difference between treatments for each chemical element and challenge. Different uppercase letters indicate differences between challenge for each treatment and chemical element (Student-Newman-Keuls' method, $n=10, P<0.05$ )

observe great deposition of calcium phosphate in placebo and 1100 ppm $\mathrm{F}$ toothpastes, even the dentin being maintained overnight in artificial saliva.

Despite the reduction of $\mathrm{Ca}, \mathrm{P}$, and $\mathrm{O}$ after acid challenge, the $\mathrm{Ca} / \mathrm{P}$ ratio was 1.53 (TMPmicro) and 1.57 (TMPnano) for the TMP-containing toothpastes, which

a

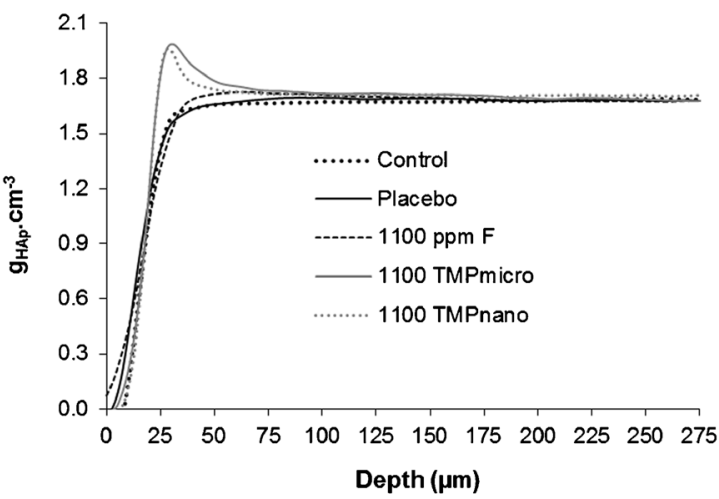

C

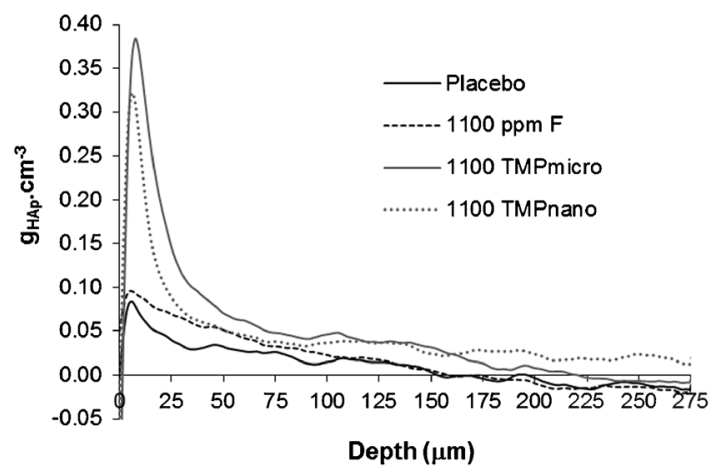

Fig. 2 Cross-sectional profile of mineral concentration $\left(\mathrm{g}_{\mathrm{HAp}} \mathrm{cm}^{-3}\right)$ as a function of dentin depth $(\mu \mathrm{m})$ after treatment with toothpastes or not (control group) (a) and after treatments followed by acid challenge (b), according to the groups obtained by micro-CT. Differential mineral concentration profile $\left(\mathrm{g}_{\mathrm{HAp}} \mathrm{cm}^{-3}\right)$ obtained by subtracting the values of still resembles an apatite. Thus, it can be considered that this collagen remained highly mineralized and the dentinal tubules obliterated, suggesting a greater interaction between mineral (calcium phosphate) and protein (collagen: atomic $\%$ of $\mathrm{C}$ and $\mathrm{N}$ after acid challenge $>$ no acid) parts of dentin, like a "melt" of calcium phosphate/collagen.

b

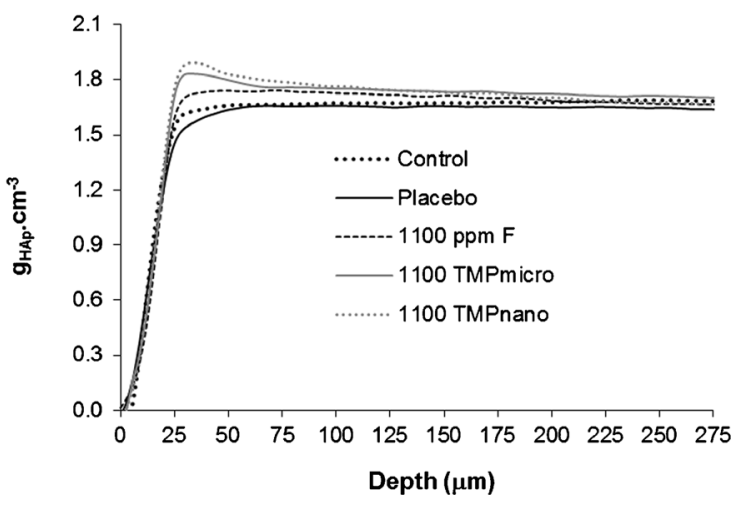

d

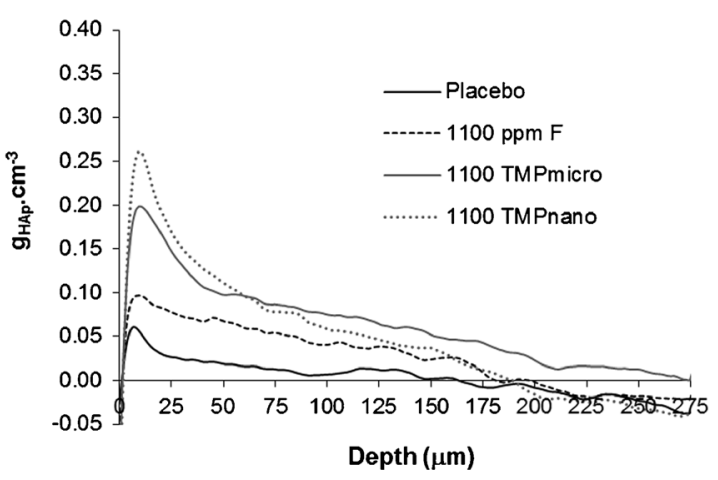

mineral concentration of the control group from those of the toothpastes groups (i.e., placebo, 1100 ppm F, 1100 TMPmicro, and 1100 TMPnano group values minus the control group values) at each depth $(\mu \mathrm{m})$ after treatment $(\mathbf{c})$ and after treatment followed by acid challenge (d) 
Although the mineral concentration (IM; $\mathrm{g}_{\text {HAp }} \mathrm{cm}^{-3} \times \mu \mathrm{m}$ ) decreased at $\sim 20 \mu \mathrm{m}$ outer dentin for TMP toothpastes, the IM was not altered after acid challenge. The acid challenge was mild probably due to the short time of immersion, since the $\mathrm{pH}$ of citric acid was similar to that of fruit juices $[25,26]$. After dissolution, the re-precipitation of calcium phosphate led to a greater mineral concentration into the dentinal tubules between 40 and $200 \mu \mathrm{m}$ of depth. This phenomenon also occurred with 1100 ppm F toothpaste, with a tendency of increase in mineral concentration. This increase of mineral concentration in depth, even after acid challenge, suggests that a fluoride toothpaste containing TMP could have a great impact in the reduction of dentin hypersensitivity. However, in vitro studies of hydraulic conductance must be carried out to prove that hypothesis.

Study with caries model shows that reduction of the TMP particle size increases its ability to promote remineralization when associated to $1100 \mathrm{ppm} F$ toothpaste [17], which led to its use in the present study. However, utilizing dentin, the reduction of particle size did not imply in greater dentinal obliteration or mineral content (Table 1). Dentin and enamel are different substrates, dentin being more reactive than enamel [38]. Furthermore, dentin presents more linking sites from hydroxyapatite $(\mathrm{OH})$ and collagen $\left(\mathrm{NH}_{2}\right)$, which provides more possibilities for TMP adsorption. Thereby, the amount of TMP adsorbed was determined by the higher reactivity of dentin rather than the size of TMP particles. However, TMP nanoparticles are more reactive and induced the precipitation of homogeneous calcium phosphate with lower size (Fig. 1g) compared to microparticles TMP (Fig. 1e). This can influence the hydraulic conductance and must be tested. Nevertheless, the higher reactivity of nanoparticles brings concern about their safety. Usually, the main health risk is related to nanoparticle inhalation, which is absent in our study since TMP nanoparticles were immersed in a wet medium (toothpastes), therefore trapped by thermodynamic forces. Actually, injuries involve mainly oxidative processes by the generation of reactive oxygen species that are absent in metaphosphates (trimetaphosphate and hexametaphosphate) [39]. There are no studies reporting toxicity in humans due to crystalline oxide nanoparticles in sunscreens or cosmetics, and only the presence of reactive sites on the nanoparticle could make it toxic. In fact, TMP is used as buffering agent in cosmetic formulations and does not cause side effects at concentrations below $10 \%$ [40].

Based on the results, it was concluded that the addition of TMP to toothpastes containing $1100 \mathrm{ppm} \mathrm{F}$ produced significantly greater obliteration of dentinal tubules and higher mineral concentration when compared to 1100 ppm F toothpaste. The size of TMP particles (micro or nano) had no effect on the obliteration of dentinal tubules and mineral concentration of dentin.
Acknowledgments The authors acknowledge the financial support of scholarship provided by the National Council for Scientific and Technological Development (CNPq 140532/2014-5) and the research support granted by the São Paulo Research Foundation (FAPESP 2013/25531-9). The authors also thank the Multi-User Laboratory of FOA-UNESP and FINEP (FINEP/CT-INFRA-Agreement FINEP: 01.12.0530.00-PROINFRA 01/2011) for providing the high-resolution computed microtomography system (SkyScan Model 1272) for the analysis of this study.

Funding The work was supported by the São Paulo Research Foundation (FAPESP 2013/25531-9) and the scholarship provided by National Council for Scientific and Technological Development (CNPq 140532/ 2014-5).

\section{Compliance with ethical standards}

Conflict of interest The authors Alberto Carlos Botazzo Delbem and Emerson Rodrigues Camargo declare that have a patent request in Brazil (INPI-BR 102014025902-3 A2) for "Formulation of fluoride dentifrice." The authors Carla Oliveira Favretto, João Carlos Silos Moraes, Priscila Toninatto Alves de Toledo, and Denise Pedrini declare that they have no conflict of interest.

Ethical approval All procedures performed in studies involving human participants were in accordance with the ethical standards of the Institutional Review Board and with the 1964 Helsinki declaration and its later amendments or comparable ethical standards.

Informed consent Informed consent was obtained from all individuals participating in the study.

\section{References}

1. Brannstrom M (1963) Hydrodynamic mechanism in the transmission of pain producing stimuli through dentine, in: D.J. Anderson (Ed), Sensory mechanism in dentine, Pergamon, Oxford, 37-79

2. Suge T, Ishikawa K, Kawasaki A, Yoshiyama M, Asaoka K, Ebisu S (1995) Effects of fluoride on the calcium phosphate precipitation method for dentinal tubule occlusion. J Dent Res 74:1079-1085

3. Dolci G, Mongiorgi R, Prati C, Valdre G (1999) Calcium phosphates produced by physical methods in the treatment of dentin hypersensitivity. Minerva Stomatol 48:463-476

4. Suge T, Ishikawa K, Kawasaki A, Suzuki K, Matsuo T, Noiri Y, Imazato S, Ebisu S (2002) Calcium phosphate precipitation method for the treatment of dentin hypersensitivity. Am J Dent 15:220-226

5. Pereira JC, Martineli ACBF, Tung MS (2002) Replica of human dentin treated with different desensitizing agents: a methodological SEM study in vitro. Braz Dent J 13:75-85

6. Shetty S, Kohad R, Yeltiwar R (2010) Hydroxyapatite as an inoffice agent for tooth hypersensitivity: a clinical and scanning electron microscopic study. J Periodontol 81:1781-1789

7. Wang Z, Jiang T, Sauro S, Pashley DH, Toledano M, Osorio R, Liang S, Xing W, Sa Y, Wang Y (2011) The dentine remineralization activity of a desensitizing bioactive glasscontaining toothpaste: an in vitro study. Aust Dent J 56:372-381

8. Erdemir U, Yildiz E, Kilic I, Yucel T, Ozel S (2010) The efficacy of three desensitizing agents used to treat dentin hypersensitivity. J Am Dent Assoc 141:285-296

9. Sauro S, Watson TF, Thompson I (2010) Dentine desensitization induced by prophylactic and air-polishing procedures: an in vitro 
dentine permeability and confocal microscopy study. J Dent 38 : $411-422$

10. Miglani S, Aggarwal V, Ahuja B (2010) Dentin hypersensitivity: recent trends in management. J Conserv Dent 13:218-224

11. Yang ZY, Wang F, Lu K, Li YH, Zhou Z (2016) Argininecontaining desensitizing toothpaste for the treatment of dentin hypersensitivity: a meta-analysis. Clin Cosmet Investig Dent 8:1-14

12. Wilchgers TG, Emert RL (1997) Dentin hypersensibility. Oral Health 87:51-57

13. Arrais CA, Micheloni CD, Giannini M, Chan DC (2003) Occluding effect of dentifrices on dentinal tubules. J Dent 31:577-584

14. Souza JAS, Amaral JG, Moraes JCS, Sassaki KT, Delbem ACB (2013) Effect of sodium trimetaphosphate on hydroxyapatite solubility: an in vitro study. Braz Dent J 24:235-240

15. Delbem ACB, Souza JAS, Zaze ACSF, Takeshita EM, Sassaki KT, Moraes JCS (2014) Effect of trimetaphosphate and fluoride association on hydroxyapatite dissolution and precipitation in vitro. Braz Dent J 25:479-484

16. De Castro LP, Delbem AC, Danelon M, Passarinho A, Percinoto C (2015) In vitro effect of sodium trimetaphosphate additives to conventional toothpastes on enamel demineralization. Clin Oral Investig 19:1683-1687

17. Danelon M, Pessan JP, Neto FN, Camargo ER, Delbem AC (2015) Effect of toothpaste with nano-sized trimetaphosphate on dental caries: in situ study. J Dent 43:806-813

18. Viana PS, Machado AL, Giampaolo ET, Pavarina AC, Vergani CE (2010) Microwave irradiation disinfection of bovine enamel. Caries Res 44:349-357

19. Rusin RP, Agee K, Suchko M, Pashley DH (2010) Effect of a new desensitizing material on human dentin permeability. Dent Mater 26:600-607

20. Ohtani O (1987) Three-dimensional organization of the connective tissue fibers of the human pancreas: a scanning electron microscopic study of $\mathrm{NaOH}$ treated-tissues. Arch Histol Jap 50:557-566

21. Ushiki T, Ide C (1990) Three-dimensional organization of the collagen fibrils in the rat sciatic nerve as revealed by transmission and scanning electron microscopy. Cell Tissue Res 260:175-184

22. Souza MDB, Pessan JP, Lodi CS, Souza JAS, Camargo ER, Souza Neto FN, Delbem ACB (2017) Toothpaste with nanosized trimetaphosphate reduces enamel demineralization. JDR Clinical \& Translational Research 2:233-240

23. Delbem AC, Sassaki KT, Vieira AE, Rodrigues E, Bergamaschi M, Stock SR, Cannon ML, Xiao X, De Carlo F, Delbem AC (2009) Comparison of methods for evaluating mineral loss: hardness versus synchrotron microcomputed tomography. Caries Res 43:359365

24. Schipper R, Loof A, De Groot J, Harthoorn L, Dransfield E, van Heerde W (2007) SELDI-TOFMS of saliva: methodology and pretreatment effects. J Chromatogr B 847:45-53
25. Hanan SA, Marreiro RO (2009) Evaluation of the $\mathrm{pH}$ of soft drinks, juices and dairy beverages produced in the city of Manaus/AM, Brazil. Pesq Bras Odontoped Clin Integr 9:347-353

26. Barac RJ, Gasic J, Trutic N, Sunaric S, Popovic J, Djekic P, Radenkovic G, Mitic A (2015) Erosive effect of different soft drinks on enamel surface in vitro: application of stylus profilometry. Med Princ Pract 24:451-457

27. Dowker SE, Elliott JC, Davis GR, Wassif HS (2003) Longitudinal study of the three-dimensional development of subsurface enamel lesions during in vitro demineralization. Caries Res 37:237-245

28. Dowker SE, Elliott JC, Davis GR, Wilson RM, Cloetens P (2004) Synchrotron X-ray microtomographic investigation of mineral concentrations at micrometer scale in sound and carious enamel. Caries Res 38:514-522

29. Li X, Chang J (2008) Preparation of bone-like apatite-collagen nanocomposites by a biomimetic process with phosphorylated collagen. J Biomed Mater Res A 85:293-300

30. Leone G, Torricelli P, Giardino R, Barbucci R (2008) New phosphorylated derivatives of carboxymethylcellulose with osteogenic activity. Polym Adv Technol 19:824-830

31. Moretto MJ, Delbem ACB, Manarelli MM, Pessan JP, Martinhon CCR (2013) Effect of fluoride varnish supplemented with sodium trimetaphosphate on enamel erosion and abrasion: an in situ/ex vivo study. J Dent 41:1302-1306

32. Manarelli MM, Delbem AC, Binhardi TD, Pessan JP (2015) In situ remineralizing effect of fluoride varnishes containing sodium trimetaphosphate. Clin Oral Investig 19:2141-2146

33. Takeshita EM, Danelon M, Castro LP, Sassaki KT, Delbem AC (2015) Effectiveness of a toothpaste with low fluoride content combined with trimetaphosphate on dental biofilm and enamel demineralization in situ. Caries Res 49:394-400

34. Raynaud S, Champion E, Bernache-Assollant D, Thomas P (2002) Calcium phosphate apatites with variable $\mathrm{Ca} / \mathrm{P}$ atomic ratio $\mathrm{I}$. Synthesis, characterisation and thermal stability of powders. Biomaterials 23:1065-1072

35. Dorozhkin SV (2010) Amorphous calcium (ortho) phosphates. Acta Biomater 6:4457-4475

36. Forien JB, Fleck C, Krywka C, Zolotoyabko E, Zaslansky P (2015) In situ compressibility of carbonated hydroxyapatite in tooth dentine measured under hydrostatic pressure by high energy X-ray diffraction. J Mech Behav Biomed Mater 50:171-179

37. Buzalaf MA, Hannas AR, Kato MT (2012) Saliva and dental erosion. J Appl Oral Sci 20:493-502

38. Buzalaf MAR, Pessan JP, Honório HM, ten Cate JM (2011) Mechanisms of action of fluoride for caries control. Monogr Oral Sci 22:97-114

39. Nel A, Xia T, Mädler L, Li N (2006) Toxic potential of materials at the nanolevel. Science 311:622-627

40. Lanigan RS (2001) Final report on the safety assessment of sodium metaphosphate, sodium trimetaphosphate, and sodium hexametaphosphate. Int J Toxicol 20:75-89 